CULTURE\& SOCIETY JOURNAL OF ANTHROPOLOGICAL REEEARCH
Culture \& Society: Journal of Anthropological Research

VOL. 1 NO. 3 MARET 2020

http://culture.ppj.unp.ac.id

Email: culture@ppj.unp.ac.id

ISSN: 2686-343X (E-ISSN) 2686-3421 (P-ISSN)

DOI: https://doi.org/10.24036/csjar.v1i3.28

\title{
Pendidikan Inklusi Berbasis Nilai Kearifan Lokal di SEKOLAHALAM MINANGKABAU Kota Padang Sumatera Barat
}

\author{
Witra Alti \\ Universitas Negeri Padang \\ Email: witra.alti@yahoo.com
}

\begin{abstract}
Abstrak
Pendidikan inklusi di Indonesia dilakukan berlandasan nilai-nilai dari luar, namun seharusnya ada nilai-nilai daerah yang arif dan menjadi landasan dalam penerapan pendidikan inklusi yaitu nilai-nilai kearifan lokal. Penelitian ini mencoba untuk mengungkapkan nilai-nilai kearifan lokal minagkabau yang merupakan bentuk dari pendidikan inklusi. Penelitian ini menggunakan pendekatan kualitatif. Dilakukan dengan cara observasi partisipasif pasif dan wawancara terstruktur di sekolahalam minangkabau. Teknik pemilihan infroman yaitu porposif sampling. Analis data yang digunakan adalah teknik analisis interaktif Miles dan Huberman. Hasil dari penelitian terdapat dua point penting nilai-nilai kearifan lokal yang menjadi landasan dalam pelaksanaan pendidikan inklusi di sekolahalam minangkabau, pertama filsafat Minangkabau "yaitu nan buto paambui lasuang, nan pakak palapeh badiah, nan lumpuah paunyi rumah, nan kuai pambao baban, nan pusuang disuruah-suruah, nan cadiak lawan barundiang"(yang buta penghembus lesung, yang tuli pelepas badil, yang lumpuh penghuni rumah, yang kuat memikul beban, yang bodoh disuruh-suruh, yang pintar lawan berunding), kedua kato nan ampek.
\end{abstract}

Kata kunci: kearifan lokal, pendidikan inkulsi, sekolahalam

\section{Abstract}

Inclusive education in Indonesia is based on external values, but there should be local values that are wise and become the foundation in the application of inclusive education, namely the values of local wisdom. This research tries to reveal the values of local wisdom of Minagkabau which is a form of inclusive education. This research uses a qualitative approach. Conducted by passive participatory observation and structured interviews in the sekolahalam minangkabau. The infroman selection technique is porposive sampling. The data analyst used was Miles and Huberman's interactive analysis technique. The results of the study there are two important points of the values of local wisdom that form the basis of the implementation of inclusive education in Minangkabau Schools, first Minangkabau philosophy namely "nan buto paambui lasuang, nan pakak palapeh badiah, nan lumpuah paunyi rumah, nan kuai pambao baban, nan pusuang disuruah-suruah, nan cadiak lawan barundiang(who blind is the blow of mortar, who deafisthelooser of badil, who paralyzed is the occupant of house, who strong is the carry of load, who foolishisthecommanded, who clever is the discuss of opponent)" and the values of kato nan ampek.

Key word: Local Wisdom, Inklusif of Education, School of Natur

\begin{tabular}{l|l|l} 
Received: December 6, 2019 & Revised: January 9, 2019 & Published: January 29, 2020
\end{tabular}

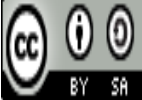

Culture \& Society: Journal of Anthropological Research Vol. 1, No. 3, Th. 2020 


\section{Pendahuluan}

Pendidikan Inklusi Merupakan suatu pendekatan pendidikan yang inovatif dan strategis untuk memperluas akses pendidikan bagi semua anak berkebutuhan khusus termasuk anak penyandang cacat (Sunaryo, 2016: 185). Konsep tersebut menjelaskan bahwa pendidikan inklusi merupakan pendidikan yang tidak membedakan peserta didik atau anak, karena peserta didik memiliki kemampuan yang berbeda dalam diri masing-masing. Pada dasarnya pendidikan inklusi dilandasi bahwa pendidikan merupakan sebagai hak azasi manusia. Seperti halnya yang dijelaskan oleh Sue Stubbs bahwa isu utama bahwa pendidikan inklusi didasarkan pada hak asasi dan model sosial, sistem yang harus disesuaikan dengan anak, bukan anak yang menyesuaikan diri dengan sistem (Stubbs, 2012: 10). Selain itu dengan adanya pendidikan inklusi mereka para peserta didik yang memiliki kecerdasan luar biasa tidak termarjinalkan dalam mengikuti pendidikan sesuai dengan hak tiap-tiap mereka.

Konsep pendidikan inklusi tercipta karena adanya pemahaman bahwa pendidikan sebagai hak asasi manusia. Dijelaskan oleh Sue Stubbs, awal mula pendidikan sebagai hak untuk semua anak telah tercantum dalam berbagai instrumen internasional mulai dari Deklarasi Universal 1948 (Stubbs, 2012: 8), serta terus disosialisasikan dan terjadi perubahan serta perbaikan sampai pada saat sekarang ini. Selain landasan secara global, pendidikan inklusi di Indonesia juga telah tercantum dalam UUD Republik Indonesia Nomor 20 tahun 2003 tentang pendidikan nasional yang membahas mengenai pendidikan inklusi. Pada pasal 15 menjelaskan bahwa, pendidikan khusus merupakan pendidikan untuk perserta didik yang abnormal atau memiliki kecerdasan luar biasa yang diselenggarakan secara inklusi atau berupa satuan pendidikan khusus pada tingkat pendidikan dasar dan menengah (Nurvitasari dkk, 2018: 15-16)

Pendidikan inklusi di Indonesia yang selalu mengacu ke nilai-nilai pendidikan inklusi di negara-negara lain yang telah dahulu menerapkan di sistem pendidikan formalnya. Tidak dapat dipungkiri bahwa Indonesia akan mencoba bercermin dan menerapkan nilai-nilai tersebut. Namun apakah nilai-nilai tersebut dapat dicerna oleh masyarakat Indonesia dengan budaya dan perspetif yang beragam ini. Maka dari itu diperlukanlah bentuk pendidikan yang menjalankan pendidikan inklusi serta juga pendidikan yang mampu mengembangkan budaya lokal untuk dijadikan landasan dalam menjalankan proses pendidikan, baik itu dalam transmisinya ataupun dalam mengembangkannya.

Bentuk pendidikan yang melandasi nilai-nilai budaya dalam proses pelaksanaan pendidikan inklusi seperti ini terlihat didalam konsep sekolahalam salah satunya yaitu sekolahalam minangkabau yang bertempat di Kota Padang. Konsep sekolahalam dijelaskan oleh Suhendri dan Murdiana (dalam Nurvitasari dkk, 2018: 16) bahwa sekolahalam merupakan salah satu jawaban atas perbaikan sistem pendidikan yang seragam dan bertujuan untuk mengembangkan potensi anak sesuai dengan kemampuannya. Nilai-nilai sekolahalam ini pada dasarnya sama dengan pendidikan inklusi. Sekolahalam, sebagai bentuk dari salah satu lembaga pendidikan alternatif belum banyak di jumpai di kalangan pendidikan. Hal ini karena sekolahalam dekat dengan berbagai aktivitas yang lebih banyak dilakukan di alam terbuka. Menurut Leandonowo (penggagas Sekolahalam di Indonesia) dalam Nurvitasari bahwa sekolahalam lebih memfokuskan pada alam untuk kebahagiaan (Novitasari dkk, 2018: 16).

Pada umumnya para penggagas sekolahalam, memberikan kewenangan kepada setiap pendiri sekolahalam untuk membuat sistem tersendiri yang sesuai dengan kondisi sosial budaya di tempat sekolah itu berdiri. Hal itu juga berpengaruh terhadap penanaman nilai-nilai dalam melaksanakan pendidikan inklusi di setiap sekolahalam, dan juga pastinya ini akan berpengaruh terhadap sekolahalam minangkabau. Hal ini diungkapkan oleh pengelolah sekaligus fasilitator sekolahalam mingkabau bapak Ade Rahardian.

Nilai-nilai budaya lokal yang sering kita sebut kerifan lokal menjadi landasan dalam pelaksanaan pendidikan inklusi di sekolahalam minangkabau, hal tersebut dipaparkan oleh salah seorang pengelolah sekolah ini yaitu bapak Ade Rahardian, ia menyebutkan bahwa sekolahalam minangkabau menyandang nama minangkabau maka nilai-nilai yang diambil dalam kegiatan

Culture \& Society: Journal of Anthropological Research Vol. 1, No. 3, Th. 2020 
sekolah dan pembelajaran mengacuke nilai-nilai minangkabau. Nilai-nilai kearifan lokal seharusnya digunakan dalam sistem pendidikan biasa dan juga pendidikan inklusi. Hal ini akan lebih memudahkan para pendidik untuk mentransmisikan nilai-nilai tersebut dalam kehidupan siswa karena nilai-nilai tersebut tumbuh dan berkembang di lingkungan kelompok mereka. Hal ini sepadan dengan apa yang disampaikan oleh Ronald Fransyaigu dalam jurnalnya bahwa untuk mentranmisikan nilai-nilai baik atau karakter, sepertihalnya pendidikan inklusi syarat di dalamnya nilai-nilai karakter seperti saling menghormati dan menghargai. Cara yang dapat dilakukan yaitu dengan cara proses pembelajaran yang berlandasan nilai-nilai kearifan lokal, karena kearifan local merupakan kebenaran yang telah menjadi tradisi daerah yang memilikinya serta merupakan landasan atau pedoman yang bersumber dari nilai ke-Tuhanan dan berisi dengan nilai-nilai yang baik dan arif (Ronald Fransyaigu, n.d.).

Selain itu juga terdapat penelitian yang dilakukan oleh Ahmad Fauzi (Fauzi, 2017) tentang Pendidikan Inklusi Berbasis kearifan Lokal dalam Praktik Sosial di Pesantern Zainul Hasan Genggo Probolinggo Jawa Timur, menjelaskan bahwa pendidikan islam inklusi sejatinya merupakan transformasi nilai-nilai kearifan lokal di pondok pesantren yaitu baraqah yang bersumber pada Al-Quran dan Al-hadists sebagai keyakinan dan nilai dasar dengan mengedepankan sikap saling menghormati tentang perbedaan dan memelihara keselarasan hidup yang bertumpu pada sistem nilai sosial tersebut. Penelitian inilah yang menjadikan rujukan bahwasanya nilai-nilai kearifan lokal itu biasa digunakan dalam proses pendidikan inklusi.

Ketika berbagai sekolah mencoba menggunakan nilai-nilai yang didapat secara nasional, sekolahalam minangkabau mencoba untuk mengungkapkan bahwa penerapan pendidikan inklusi bisa dengan menggunakan nilai-nilai kearifan lokal yang secara tidak langsung dapat lebih muda dicerna dan diterima oleh siswa. Maka dari hal ini peneliti ingin mencoba mengungkapkan apa nilai-nilai kearifan lokal yang menjadi landasan dalam melaksanakan pendidikan inklusi di sekolahalam minangkabau. Tujuan dari penelitian ini adalah untuk mengungkapkan nilai-nilai kearifan lokal yang di sekolahalam minangkabau dan diharapkan nanti bisa dijadikan rujukan dalam pelaksanaan pendidikan inklusi diberbagai sekolah di Kota Padang.

\section{Metode Penelitian}

Penelitian ini menggunakan pendekatan kualitatif, karena ingin melihat kondisi sosial yang terjadi di lapangan (Sugiyono, 2012:7) dilakukan dengan cara observasi partisipasif pasif dengan mengamati beberapa rangkaiaan kegiatan disekolah serta data diperoleh melalui wawancara terstruktur dan lepas pada pedoman wawancara mengenai landasan nilai kearifan lokal yang digunakan dalam melaksanakan pendidikan inklusi. Untuk melengkapi teknik pengumpulan data digunakan alat pencatatan dan perekaman. Dilakukan di sekolahalam minangkabau, dengan teknik pemilihan infroman yaitu porposif sampling (Suyanto, 1995), dengan beberapa informan yaitu pengurus sekolah, guru, siswa dan tenaga kependidikan. Penelitian dilakukan pada waktu sekolah dan kegitatan pembelajaran berlangsung. Analisis data yang digunakan adalah teknik analisis interaktif Miles dan Huberman (Sugiyono, 2012), yaitu data yang didapat dari wawancara telah jenuh dengan hasil wawancara yang sama diberikan oleh tiap informan.

\section{Hasil dan Pembahasan}

Dalam hal ini penulis menemukan hasil dari penelitian lapangan yang berhubungan dengan pendidikan inklusi yang berbasis nilai-nilai kearifan lokal di sekolahalam minangkabau. Diantaranya bahwa terdapat perbedaan sekolahalam minangkabau dengan sekolah umum lainya, nilai-nilai kearifan lokal yang dijalankan dalam penerapan pendidikan inklusi di sekolahalam minangkabau: 


\section{Perbedaan sekolahalam minangkabau Dengan Sekolah Umum}

Melihat perbedaan sekolahalam dengan sekolah umum biasanya, hal yang pertama yang seyogyakan kita tahu beberapa hal. Salah satu sekolahalam yang ada di Kota Padang yaitu sekolahalam miangkabau. Dari namanya kita dapat menyimpulkan bahwa sekolah ini ada identiknya dengan Minangkabau. Terletak di Kota Padang jln Ujung Pandang No. 11 Kel. Ulak Karang Selatan, Kec Padang Utara. Berdasarkan penjelasan dari bapak Ade Rahardian salah seorang pengurus sekolahalam minangkabau, bahawa sekolah ini berdiri di bawah naungan Yayasan Pelita Aksara, dulunya merupakan sebuah Pendidikan Anak Usia Dini (PAUD) untuk anak-anak usia 0-6 tahun yang bernama Pelita Aksara Child Care \& Education. Sekolah ini mulai dirintis pada Hari Jum'at, 24 Februari 2006, bertepatan dengan 25 Muharram 1427 Hijriyah.

Ada hal yang menarik dari nama sekolah ini, jika dilihat nama sekolaalam minangkabau ditulis tidak dengan standar penulisan yang benar seperti antara "sekolah" dan "alam" itu disatukan serta "minangkabau" huruf awal tidak besar. Hal ini karena sekolahalam minagkabau memiliki filsafah sendiri dengan nama sekolah mereka. Hal ini dijelaskan oleh bapak Ade Rahadian salah seorang pengurus sekolahalam minangkabau, bahawa penulisan nama sekolah "sekolahalam" itu tidak di pisahkan karena memiliki artian bahwa sekolah dan alam itu menyatu saling terikat satu sama lain. Serta penulisan "sekolahalam minangkabau" huruf awal tidak besar hal ini karena memiliki filosofi setara yaitu sama tinggi maka jika di tulis dengan huruf besar maka harus besar semua begitu pun sebaliknya. Hal ini lah yang dilakukan ke pada siswa-siswa bahwa setiap siswa itu sama dan memiliki kemampuan masing-masing. Berdasarkan nama telah terdapat perbedaan sekolahalam minangkabau dan sekolah umum biasa. Perbedaan lain yang didapat melalui hasil observasi yaitu:

\section{Tempat Belajar}

Sekolahalam adalah sekolah yang proses belajarnya dan cara belajarnya menggunakan alam atau sekolah yang menggunakan pendekatan pada alam (Cecep Yudistira, 2014: 2). Berdasarkan observasi, sekolahalam minangkabau tidak jauh berbeda dengan deskripsi konsep yang dijelaskan dalam Cecep Yudistira bahwa sekolahalam mianangkabau di Kota Padang merupakan bentuk sistem pendidikan yang menggunakan alam sebagai tempat belajar. Proses belajar dilakukan di kelas-kelas yang tebuka dan langsung bersentuhan dengan alam, belajar duduk dilantai sama tinggi, para guru di sekolahalam ini tidak hanya sebagai pengajar tetapi juga bisa menjadi sahabat bagi setiap peserta didik. Dari hal ini dapat terlihat perbedaan antara bagaimana sekolahalam dengan sekolah pada umumnya. Sekolah umum yang lebih bersifat formal banyak melaksanakan pembelajaran didalam kelas, dengan menggunakan meja-meja dan papan tulis yang dietakkan didepan kelas.

\section{Nilai-nilai yang Melandasi}

Perbedaan sekolah alam miangkabau dengan sekolah formal biasa terletak pada tujuan serta nilai yang diharapkan tertanam dalam diri siswa. Sekolah formal biasa melaksanakan pendidikan sesuai dengan tujuan pendidikan yang dijelaskan dalan UU No. 20 tahun 2003 yaitu pendidikan nasional bertujuan untuk berkembangnya potensi peserta didik menjadi manusia yang beriman dan bertakwa kepada Tuhan Yang Maha Esa, berakhlak mulia, sehat, berilmu, cakap, kreatif, mandiri dan menjadi warga negara yang demokrasi serta bertanggung jawab (Undang-Undang Republik Indoneesia Nomor 20 Tahun 2003 Tentang Sistem Pendidikan Nasional, 2006).

Sedangkan sekolahalam minangkabau sendiri memilik tiga pilar yang menjadi landasan yang menjadi patokan dalam melaksanakan sistem pendidikan di sekolahalam minangkabau, hal ini disampaikan oleh Ade Rahadian salah satu pengurus sekolahalam minangkabau, beliau menjelaskan bahwa tiga pilar tersebut yaitu: 


\section{Akhlakul Karimah}

Nilai-nilai yang mengacu pada nilai-nilai keagamaan. Siswa diharapkan memiliki nilainilai yang mencerminkan prilaku ke-Tuhanan dimana ke-Tuhanan disini erat kaitannya dengan nilai agama islam, karena masyarakat Minangkabau identik dengan masyarakat yang mempercayai agama islam dan selalu diakitkan dengan kebudayaan Minangkabau yaitu adat basandi sarak sarak basandi kitabulallah.

\section{Budaya}

Agama dan budaya didalam minangkabau tidak dapat dipisahkan, yaitu alam basandi sarak sarak basandi kitabullah, seperti yang telah dijelaskan sebelumnya. Kebudayaaan Minangkabau tidak dapat dilepaskan dalam praktek pendidikan di sekolahalam minangkabau. Budaya Minangkabau menjadi salah satu nilai yang ditransmisikan, dikarenakan sekolahalam minangkabau membawa nama minagkabau sehingga nilai-nilai yang dipakai adalah nilai-nilai budaya minang. Seperti halnya disampaikan oleh pengurus sekolah ini bahwa sekolah ini merupakan bentuk lain dari pendidikan surau.

\section{Kepemimpinan}

Siswa diharapkan mampu memiliki nilai kepemimpinan ini, dimulai dari hal kecil seperti mampu memimpin diri sendiri. Nilai kepemimpinan ini pada dasarnya jika disamakan dengan tujuan pendidikan Indonesia termasuk dalam bagian dari siswa memiliki ilmu pengetahuan. Namun yang menjadi perbedaan adalah bahwa sekolahalam minagkabau mengajarkan ilmu bukan sekedar hapalan tetapi mencoba untuk mengajarkan bagaimana bisa mengamalkan ilmu tersebut dalam kehidupannya. Ade Rahardian juga memaparkan kenapa pilar ini menjadi landasan dalam pelaksanaa dalam sekolahalam minagkabau bahwa masih banyak realitas yang kita lihat bahwa terdapat beberapa peserta didik yang telah tamat di jenjang SMA atau pun perkulihan, kadang kurang mampu untuk mandiri. Salah satu faktor karena pendidikan hanya berupa transfer pengetahuan tanpa ada praktek oleh siswa-siswa.

Dari penjelasan diatas terlihat bahwa sekolahalam minangkabau memiliki nilai-nilai standar sendiri dalam pelaksanaan pendidikan dan peoses pembelajarannya. Nilai ini memiliki perbedaan sedikit dengan sekolah formal biasanya. Namun jika dilihat dasarnya memang dari standar nilai Tujuan Pendidikan Nasional namun nilai-nilai arif lokal budaya Minangkabau juga ikut berkontribusi. Hasil observasi pun menggamabarkan bahwa di sekolahalam minangkabau tidak pernah mengacu kepada nilai yang dihasilkan siswa dalam akhir pembelajaran namun bagaimana proses dalam kegiatan pembelajaran yang lebih ditonjolkan.

\section{Nilai-Nilai Kearifan Lokal di SEKOLAALAM MINANGKABAU Dalam Menjalankan Pendidikan Inklusi}

Setelah melakukan observasi, terdapat beberapa point penting nilai-nilai yang ditanamkan dalam praktek pendidikan karakter dalam sekolahalam minangkabau ini. Hal yang peneliti kaji disini berhubungan dengan nilai-nilai yang dijadikan sebagai pedoman oleh sekolahalam minangkabau dalam pelaksanaan pendidikan inklusi. Nilai-nilai tersebut yaitu:

\section{Nilai Falsafah Minangkabau}

Minagkabau identik dengan falsafahnya. Berbagai macam falsafah Minangkabau yang berkaitan dengan nilai-nlai tingkahlaku dan nilai-nilai dasar masyarakat minang. Dari hasil observasi salah satu nilai filsafah yang berkaitan dengan penanaman nilai pendidikan inklusi di sekolahalam minangkabau yaitu nilai yang terkandung dalam pituah minang, hal ini disampaikan oleh salah seorang pengurus sekolahalam minangkabau yaitu bapak Ade Rahadian :

"nan buto paambui lasuang, nan pakak u badiah, nan lumpuah paunyi rumah, nan kuai pambao baban, nan pusuang disuruah-suruah, nan cadiak lawan barundiang" (yang buta penghembus lesung, yang pekak pelepas badil, yang lumpuh 
penghuni rumah, yang kuat memikul beban, yang bodoh disuruh-suruh, yang pintar lawan berunding).

Filsafah Minangkabau diatas mencerminkan bahwa, setiap orang memiliki peran masingmasing walaupun setiap orang memiliki kekurangan tiap dirinya. Filsafah diatas mengatakan bahwa nan buto paambuih lasuang, hal ini terlihat bahwa orang yang memilki kekurangan dalam penglihatan memiliki peran bahwa mereka bisa menjalankan tugas untuk menghembus lesung. Jika dikaji lebih dalam terlihat bahwa ada hal tersirat bahwa kekurangan seseorang itu pada dasarnya bukan sebagai penghambat dalam masyarakat tetapi mereka memiliki fungsi tersendiri, sesuai dengan keahlian mereka masing-masing.

Jika dilanjutkan bahwa nan pakak palapeh badiah,(yang tuli peletus badil), nan lumpuah paunyi rumah (yang lumpuh penghuni rumah), nan kuai pambao baban (yang kuat pemikul beban) nan pusuang disuruah-suruah (yang bodoh disuruh-suruh), nan cadiak lawan barundiang (yang pintar lawan berunding) jika dilihat secara tersirat maka bisa dimaknai juga point kesamaannya dengan pituah filsafat yang pertama. Bahwa kekurangan dari tiap individu itu bisa berguna untuk perkerjaan yang bisa ia laksanakan. Hal ini sesuai dengan konsep pendidikan inklusi, bahwa banyak penjelasan tentang konsep inklusi oleh Smith (Smith, 2012) yaitu pendidikan inklusi itu berarti berkomitmen untuk melibatkan siswa-siswa yang memiliki hambatan dalam setiap tingkat pendidikan mereka yang memungkinkan. Selain itu Staub dan Peack (dalam Tarmansyah, 2007) bahwa pendidikan inklusi merupakan penempatan anak berkelainan ringan, sedang, dan berat secara penuh dikelas. Penjelasan tersebut memiliki artian bahwa tidak ada pembeda pada anak dalam pendidikan, anak dianggap memiliki potensi dan kekurangan bukanlah suatu hambatan. Serta kesimpulannya bahwa bagaimana pun kekurangan seseorang itu pasti ada kelebihan dari masing-masing individu.

Hal ini terlihat bahwa sebenarnya dari dahulu nila-nilai budaya lokal atau kearifan lokal dalam masyarakat Minangkabau telah menjalankan pendidikan inklusi. Kekurangan yang ada pada diri seseorang itu memiliki kelebihan yang bisa digunakan dalam masyarakat. Hal ini sejalan dengan penjelasan Noviana Afiqoh dkk, bahwa pendidikan berbasis kearifan lokal adalah pendidikan yang mengajarkan peserta didik untuk selalu lekat dengan sitiuasi konkrit yang mereka hadapi (Afiqoh, 2018: 44). Dari penjelasan itu maka nilai-nilai inilah seharusnya ditumbuh kembangkan dalam jiwa perserta didik. Sepertinya halnya sekolahalam minangkabau yang telah mempraktekkan dalam proses pendidikannya, salah satu contoh yaitu dalam kegiatan gotong royong, peserta didik bekerjasama tanpa memandang beda siswa biasa dengan ABK (Anak Berkebutuhan Khusus). Mereka turut diikut sertakan walau yang dikerjakan mungkin hanya sedikit tetapi sikap saling menghargai dalam diri peserta didik sangatlah tampak.

\section{Nilai Adab atau Sikap Kebudayaan Minangkabau}

Dari proses observasi yang dilakukan, terdapat nilai adab atau sikap dalam masyarakat Mianangkabau yang menjadi landasan pelaksanaan pendidikan inklusi lainya yaitu kato nan ampek. Nilai-nilai kato nan ampek (yang empat) yaitu kato mandaki,kato manurun, kato mandata, dan kato malereng. Nilai-nilai yang terkandung dalam kato nan ampek ini, memiliki makna bahwa terdapat norma yang mengatur setiap individu ketika saling berinteraksi. Nilai ini mengatur bagaimana berinteraksi antara yang muda dengan yang muda dan yang tua dengan yang tua tau sebaliknya. Ada nilai yang dijadikan tolak ukur bagi setiap individu di sekolahalam miangkabau dalam berinterkasi. Nilai ini mengatur bagaimana cara berbicara dengan yang lebih tua, berbicara dengan yang lebih muda maupun dengan sesama besar tanpa memandang kondisi dari lawan bicara.

Nilai-nilai ini masuk kedalam nilai kearifan lokal karena menurut Chairiyah dalam jurnalnya menjelaskan bahawa ruang lingkup kearifan lokal terbagi menjadi delapan satu diantaranya yaitu norma-norma lokal yang dikembangkan, pantangan dan kewajiban (Chairiyah, 2017: 210). Hal ini juga diperjelas oleh Demina dimana nilai-nilai kato nan ampek

Culture \& Society: Journal of Anthropological Research Vol. 1, No. 3, Th. 2020 
dalam adat Minangkabau merupakan nilai kearifan lokal yang menggambarkan bahwa nilainilai ini menjunjun tinggi budi perketi (Demina, 2016: 206). Hal ini yang ditanamkan dalam diri setiap peserta didik di sekolahalam minangkabau.

Dari penjelasan diatas maka nilai-nilai kato nan ampek ini merupakan salah satu bentuk dari kearifan lokal masyarakat Minangkabau dalam mengatur setiap individu dalam berinterkasi dengan individu lain. Nilai-nilai ini digunakan dalam kehidupan sosialnya. Dari proses observasi yang yang dilakukan dan juga dari penjelasan diatas, nilai ini lah yang digunakan oleh sekolahalam minangkabau dalam menanamkan nilai-nilai arif dalam setiap aktifitas selama proses pembelajaran. Bukan hanya dalam proses pembelajaran disetiap kegiatan yang dilakukan oleh sekolaalam minangkabau selalu merujuk ke nilai-nilai kato nan ampek. Nilai ini lah yang juga menjadi landasan dalam melaksanakan pendidikan inklusi, karena walaupun ada beberapa siswa yang termasuk Anak Berkebutuhan Khusus (ABK) namun siswa lain tidak pernah berkata yang tidak sopan kepada siswa ABK.

Selain nilai-nilai tersebut, dari hasil observasi dan penjelasan dari salah satu pengurus sekolahalam minangkabau yaitu bapak Ade Rahardian dan juga beberapa guru salah satunya yaitu Duwi yang mengajar di kelas 5 yang sempat diwawancarai nilai lain yang sebenarnya telah menjadi kebudayaan lokal masyarakat minang, yaitu nilai adab, bagaimana yang tua menyayangi yang muda dan yang muda menghormati yang ditanamkan sejak dini. Hal ini lah yang dijalankan dan dipterapkan kepada siapapun, baik ABK maupun Non ABK. Anak selalu diajarkan tentang adab ini, bagaimana berprilaku dengan orang yang lebih tua dan bagaimana berprilaku dengan yang lebih muda.

\section{Kesimpulan}

Sistem pendidikan inklusi pada dasarnya merupakan landasan di konsep sekolahalam, namun perbedaan antara sekolahalam minangkabau dengan sekolahalam lainnya yaitu terletak pada nilai-nilai yang dianut oleh setiap sekolahalam. sekolahalam minagkabau pada dasarnya mengacuk kepada nilai-nilai kearifan lokal yang ada di dalam masyarakat minang.

Nilai-nilai yang diambil dan dijadikan landasan dalam pelaksanaan pendidikan inklusi di dalam sekolahalam minangkabau ini yaitu terdapat dua point yang besar diluar dari nilai-nilai kebudayaan yaitu menggunakan filsafah Minangkabau yaitu nan buto paambui lasuang, nan pakak palapeh badiah, nan lumpuah paunyi rumah, nan kuai pambao baban, nan pusuang disuruah-suruah, nan cadiak lawan barundiang (yang buta penghembus lesung, yang pekak pelepas badil, yang lumpuh penghuni rumah, yang kuat memikul beban, yang bodoh disuruh-suruh, yang pintar lawan berunding). Nilai-nilai budaya Minangkabau ini pada memperlihatkan bahwa adanya nilai-nilai pendidikan inklusi yang melihat bahwa semua orang itu dengan kekurangan masing-masing pasti memiliki kelebihan yang akan bermanfaat untuk orang lain.

Point kedua yaitu nilai-nilai kato nan ampek, bahwa setiap orang diatur dalam berbicara dan beritngkahlaku dengan yang lebi muda, lebih tua dan sama besar, tanpa ada membedakan satu sama lain, tanpa adanya melihat kekurangan dari orang lain. Nilai-nilai tersebut merupakan nilai kearifan lokal yang sepatutnya dilaksanakan atau menjadi landasan dalam proses belajar. Seperti yang dijelaskan sebelumnya bahwa pendidikan yang berbasis kerarifan lokal merupakan pendidikan yang mengajarkan peserta didik untuk selalu lekat dengan situasi konkrit yang mereka hadapi. Maka nilai-nilai ini selayaknya diimplementasikan dalam pendidikan.

\section{Daftar Pustaka}

Afiqoh, N. (2018). Penanaman Nilai Kearifan Lokal dalam Pembelajaran Sejarah Pokok Bahasan Perkembangan Islam di Indonesia Pada Siswa Kelas X IPS di SMA Negeri 1 Pamotan Tahun Ajaran 2017 / 2018. Indonesian Journal of History Education, 6(1), 42-53.. Basrowi, \& S. (2009). Memahami Penelitian Kualitatif. Jakarta: Rineka Cipta. Cecep Yudistira. (2014). Implementasi Pendidikan Karakter Peduli Lingkungan di Sekolah 
Alam Unggaran Kabupaten Semarang. Skripsi. Universitas Negeri Semarang.

Chairiyah. (2017). Implementasi Pendidikan Karakter Melalui Nilai-Nilai Kearifan Lokal Di Sd Taman Siswa Jetis Yogyakarta. Jurnal Pendidikan, 4(1), 208-215.

Demina. (2016). Pembelajaran Terpadu dan Kearifan Lokal Menjunjung Tinggi Pendidikan Budi Pekerti, 15-16.

Fauzi, A. (2017). Pendidikan Inklusi Berbasis Kearifan Lokal dalam Praktik Sosia di Pesantren Zainul Hasan Genggong Proboliggo, 715-725.

Fransyaigu R. (2014). Penerapan Inkuiri Moral Berbasis Nilai-Niali Kearifan Lokal Minangkabau "Alam Takambang Jadi Guru" Untuk Pembentukan Karakter Siswa Analisis Pelaksanaan Penelitian Tindakan Kelas oleh Guru Kelas V SDN 18 Air Tawar Selatan Padang pada Mata Pelajaran PKn. Tesis. Universitas Pendidikan Indonesia

Novitasari dkk. (2018). Konsep dan Praktik Pendidikan Inklusi di Sekolah Alam Ramadhani Kediri. Ilmiah Psikologi, 3(1), 15-22.

Smith, J. D. (2012). Sekolah Inklusi: Konsep dan Penerapan Pembelajaran. Bandung: Nuansa.

Stubbs, S. (2012). Pendidikan Inklusif Ketika hanya ada sedikit sumber. The Atlas Alliance, 1-138. https://doi.org/10.17509/eh.v2i1.2755

Sugiyanto. (2012). Metode Penelitian Kualitatif Kualitatif dan R\&D. Bandung: ALFABET.

Sugiyono. (2012). Metode Penelitian Kuantitatif kualitatif dan R\&B. Bandung. Bandung: Alfabet.

Sunaryo, S. (2016). Manajemen Pendidikan Inklusif (Konsep, Kebijakan, dan Implementasinya). Jassi Anakku, 10(2), 184-200.

Suyanto, B. (1995). Metode Penelitian Sosial. Surabaya: Universitas Air Langga.

Tarmansyah. (2007). Inkusi (Pendidikan Untuk Semua). Jakarta: Depdiknas.

Undang-Undang Republik Indoneesia Nomor 20 Tahun 2003 Tentang Sistem Pendidikan Nasional. 